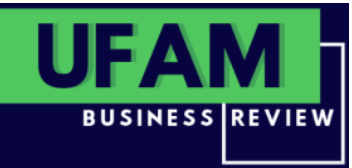

\title{
O Afazer e o Fazer da Filosofia - Oralidade e Escrita como Componentes do Ensino-Aprendizagem
}

The Doing and Doing of Philosophy - Orality and Writing as Components of Teaching and Learning

El Hacer y Hacer de la Filosofía: la Oralidad y la Escritura como Componentes de la Enseñanza y el Aprendizaje

Nelson Matos de Noronha ${ }^{1}$ Professor Titular: Universidade Federal do Amazonas, UFAM noronhanelson@ufam.edu.br http://lattes.cnpq.br/6356531305834444 https://orcid.org/0000-0003-1196-7682

Professor e Pesquisador no Programa de Pós-graduação em Sociedade e Cultura na Amazônia, no PPG de Sociologia e no PPG de Filosofia (PROF-FILO) Universidade Federal do Amazonas - UFAM, Brasil ${ }^{1}$ 


\title{
Resumo
}

Este texto foi elaborado em uma pesquisa destinada ao desenvolvimento de um estágio pósdoutoral. Nossa preocupação consiste em problematizar as restrições legais à inserção da filosofia no Ensino Médio e explorar as possibilidades da História da Filosofia como recurso didático e pedagógico. A partir de um texto de Benedito Nunes sobre a reflexão filosófica e o ensino de filosofia, tento mostrar que podemos encontrar nas publicações de Michel Foucault uma concepção de filosofia na qual o diagnóstico da atualidade se apresenta de maneira indissociável das atividades de pensar, ler, escrever e falar.

Palavras-chave: Filosofia. Ensino. Ensaio. Foucault. Kant.

\section{The Doing and Doing of Philosophy - Orality and Writing as Components of Teaching and Learning}

\begin{abstract}
This text was elaborated in a research aimed at the development of a postdoctoral internship. Our concern is to problematize the legal restrictions on the insertion of philosophy in high school and explore the possibilities of the History of Philosophy as a didactic and pedagogical resource. From a text by Benedito Nunes on philosophical reflection and the teaching of philosophy, I try to show that we can find in Michel Foucault's publications a conception of philosophy in which the diagnosis of the present presents itself inseparably from the activities of thinking, reading, write and talk.
\end{abstract}

Keywords: Philosophy. Teaching. Test. Foucault. Kant.

\section{El Hacer y Hacer de la Filosofía: la Oralidad y la Escritura como Componentes de la Enseñanza y el Aprendizaje}

\section{Resumen}

Este texto fue elaborado en una investigación dirigida al desarrollo de una pasantía postdoctoral. Nuestra preocupación es problematizar las restricciones legales sobre la inserción de la filosofía en la escuela secundaria y explorar las posibilidades de la Historia de la Filosofía como un recurso didáctico y pedagógico. A partir de un texto de Benedito Nunes sobre la reflexión filosófica y la enseñanza de la filosofía, trato de mostrar que podemos encontrar en las publicaciones de Michel Foucault una concepción de la filosofía en la que el diagnóstico del presente se presenta inseparablemente de las actividades de pensar, leer, escribe y habla.

Palabras clave: Filosofía. Docencia. Ensayo. Foucault. Kant. 


\section{INTRODUÇÃO}

A pesquisa pretende extrair das obras de Michel Foucault subsídios teóricos e metodológicos para a docência em filosofia nas condições preconizadas na Base Nacional Curricular da Educação Básica. Essa justificativa implica a exploração de recursos didáticos e pedagógicos que assegurem a qualidade do ensino-aprendizagem e a análise dos requisitos concernentes à formação do Licenciado em Filosofia pelos quais se pretende garantir sua habilitação profissional.

Após décadas de debates acirrados, em 1996, aprovou-se no parlamento nacional uma lei para disciplinar e assegurar a organização de um sistema de educação para o país. Mas isto não foi suficiente para pacificar as disputas em torno do direito à educação, de seus princípios, da distribuição das competências, obrigações, objetivos, financiamento e estrutura curricular. A lei 9394/1996 foi alterada numerosas vezes desde a sua promulgação. Além das alterações da LDB, a legislação educacional se estendeu mediante leis complementares, decretos, pareceres, diretrizes e regulamentos, resultando daí uma teia complexa que torna difícil o entendimento de sua lógica e de sua unidade.

Sem pretender explicar os fatores determinantes desse processo, para a formulação do problema, organizamos nossa discussão dividindo-a em três questões: a universalização do acesso à escola pública; as avaliações de desempenho dos estudantes brasileiros; e a ameaça do proselitismo. Como respostas para essas questões, apresentamos uma breve narrativa sobre a oralidade e a escrita na história da filosofia como base para a afirmação da tese de que o ensaio é a atividade por excelência da filosofia e, por isso, sua aplicação como recurso do ensino-aprendizagem na escola é indispensável. Para desenvolver esse argumento, apoiamo-nos na leitura foucaultiana do pensamento de Kant

\section{A UNIVERSALIZAÇÃo DO ACESSO À ESCOLA PÚBLICA}

Para alcançar a universalização do acesso à educação básica, o Estado brasileiro precisou criar políticas públicas abrangendo o financiamento da educação (incluindo subsídios para a alimentação), a formação de profissionais do magistério, a valorização desses profissionais, o sistema nacional de avaliação do desempenho dos estudantes e outras iniciativas concernentes a situações especiais. O que mobilizou múltiplos segmentos sociais, instâncias governamentais, organismos políticos, jurídicos, financeiros e assistenciais em fóruns onde nem sempre se atingiu o consenso.

A despeito da expectativa popular, a democratização do ensino tem sido atingida pela precarização das condições de oferta, sobretudo no âmbito da escola pública. Nota-se a ocorrência reiterada de comentários saudosistas a propósito do declínio de sua qualidade. Em contrapartida, as reformas que ampliaram a oferta de vagas promoveram a substituição do antigo currículo, marcadamente erudito e enciclopédico, por estruturas mais enxutas e flexíveis, voltadas para a aquisição dos conhecimentos fundamentais da leitura, da escrita, do cálculo, das ciências e dos valores cívicos e morais, além da introdução sistemática e crescente da formação para o trabalho.

Tais reformas também deram início às políticas de formação docente e ao debate sobre a necessária profissionalização do magistério como requisito indispensável à garantia da qualidade do ensino. Nessa direção, registram-se a criação e a proliferação das escolas normais, dos cursos de filosofia, dos cursos e das faculdades de pedagogia. Tais são as questões que se destacam no Parecer 277/62

UFAMBR, Manaus, v. 2, n. 1, art. 8, pp. 83-93, janeiro-junho, 2020 http://www.periodicos.ufam.edu.br/ufambr 
da Resolução, desde 1962, que estabeleceu o currículo mínimo dos cursos de filosofia, cujos princípios e a estrutura foram preservados nas Diretrizes Curriculares para a organização dos cursos de graduação em filosofia, conforme o Parecer CNE/CES 492/2001.

\section{AS AVALIAÇÕES DE DESEMPENHO DOS ESTUDANTES BRASILEIROS}

A despeito dessas dificuldades, muito se conquistou nesse campo, sobretudo no ensino fundamental e no ensino superior. A situação do ensino médio constitui um ponto crítico a partir do qual as conquistas referentes às pretensões do Estado brasileiro no domínio da universalização da educação básica têm sido contestadas. As críticas, todavia, se tornaram mais contundentes em decorrência da aplicação de processos de avaliação do desempenho dos estudantes segundo parâmetros de organismos multigovernamentais, como o Banco Mundial e a Organização Internacional do Comércio. Os resultados alcançados pelos estudantes brasileiros nas provas internacionais colocaram o país em desvantagem na classificação desses certames. O que gerou modificações substanciais na organização curricular do Ensino Médio e na proposta original da Base Nacional Comum Curricular da Educação Básica.

A justificativa para a realização dessas mudanças consiste na necessidade de assegurar uma base nacional sem prejuízo para a inserção de conhecimentos da cultura local, diversificar, flexibilizar e ao mesmo tempo garantir a qualidade do ensino de modo que os estudantes possam escolher entre os percursos formativos, no Ensino Médio, após terem adquirido os conhecimentos, as habilidades e as competências preconizados para o Ensino Fundamental. Ora, na verdade, esse argumento tem sido usado há muito tempo. Ele já estava presente nas reformas da educação empreendidas nos anos 1960 e 1970. O que de fato se encontra no centro da preocupação dos gestores do Estado é a qualificação para o trabalho, a aptidão para o cumprimento dos deveres cívicos e a reprodução do modo de vida em conformidade com a dinâmica política, econômica e social pela qual se mantêm as relações de dominação no país.

Essa maneira de pensar tem se fortalecido, uma vez que suas propostas foram aprovadas pelo parlamento brasileiro e estão sendo implementadas. Ainda que existam focos de resistência, eles ainda não são fortes o bastante para impedir ou alterar essa tendência social. Contudo, o avanço do pensamento conservador no campo da educação está longe de se tornar hegemônico, pois continuam vivos e ativos os segmentos de educadores e estudantes que contestam os discursos e as práticas pelos quais se tenta fazer da educação tão somente um dispositivo de controle. Eles acreditam que a escola e a universidade podem se tornar espaços de contestação democrática, libertação política e autonomia intelectual.

\section{A AMEAÇA DO PROSELITISMO}

Essa postura crítica e libertadora tem incomodado os atores políticos que se beneficiam das estruturas arcaicas do Estado e da Sociedade Civil, em nosso país. Na história da Educação, no Brasil, são recorrentes os discursos que denunciam ameaças de subversão, doutrinação e proselitismo entre os professores, os currículos, os livros didáticos e as metodologias inovadoras introduzidos nas instituições de Educação. Eles têm sido dirigidos preferencialmente às disciplinas

que têm como finalidade fornecer aos estudantes ferramentas intelectuais para conhecer a realidade política, social e econômica do país e desenvolver o pensamento crítico. Assim se explica a retirada, 
pela BNCC, da Filosofia e da Sociologia, como disciplinas obrigatórias, do currículo do Ensino Médio.

Desde os anos 1960, quando foram estabelecidas as Diretrizes Curriculares para os Cursos de Filosofia, esses discursos subsidiaram a redação das leis que baniram a filosofia ou criaram obstáculos para sua inserção como parte indispensável da formação escolar e acadêmica dos brasileiros. Eles argumentam que a filosofia e a sociologia abrem uma senda perniciosa para a integridade intelectual dos estudantes: o proselitismo.

Segundo essa tese, esta ameaça tende a se efetivar em um ambiente institucional favorável ao desenvolvimento de doutrinas intransigentes e dogmáticas. Como a filosofia e a sociologia dão guarida a tais doutrinas, a sua exclusão representa uma medida de prevenção contra esse risco. Além disso, tais disciplinas não atendem ao critério pelo qual se deve considerar indispensável um determinado componente curricular: a sua utilidade no mundo do trabalho. Afinal, a filosofia é um "afazer", ou seja, uma ocupação economicamente irrelevante, e não um "fazer", isto é, uma produção de bens ou uma prestação de serviços.

\section{ORALIDADE E ESCRITA NO EXERCÍCIO DA FILOSOFIA}

Segundo Benedito Nunes (2000), aqueles que se ocuparam pela primeira vez da filosofia não estiveram envolvidos com um "fazer", isto é, uma atividade produtiva, embora a produção material de algo também fosse um dos componentes de sua ocupação. Antes de se transformar em um ofício, a filosofia surgiu na esteira de uma revolução, que envolveu a invenção da escrita, a adoção da moeda e a organização da POLIS que, na Grécia Antiga, ensejou a criação do conceito de cidadania.

Testemunhas do processo de substituição da tradição oral pelo uso da escrita como prática de fixação e transmissão do saber, os filósofos pré-socráticos se dedicavam a um “afazer", isto é, uma atividade cuja finalidade não consistia em dar existência a um artefato, nem tinha como prioridade dar preceitos morais e nem mesmo alimentava outras pretensões de natureza prática. Essa atividade consistia em 'fazer ver' alguma coisa. E esse fazer ver, uma vez que não se apoiava na visão sensível, mas se tratava de um espetáculo elaborado pela reflexão, não poderia alcançar seu objetivo sem o uso das palavras. Assim, a THEORIA surgira na civilização grega da Antiguidade como "um ver intelectual por meio de conceitos" (Nunes, 2000, p. 19).

Ora, essa atividade se distinguia de uma ocupação profissional porque os que a ela se dedicavam faziam-no como partícipes de uma prática até então inédita. Tratava-se de uma forma de organização da vida na qual a linguagem assumira uma função social e política específica, não mais como recurso destinado eminentemente à instituição de rituais, códigos e mandamentos, mas sim, como uma modalidade de fazer circular na coletividade, sob a forma de argumentos, contraposição de diferentes pontos de vista e diferentes raciocínios, aquilo que deveria se tornar a visão de consenso. Nesse cenário, a filosofia se exercia mais como "ação" do que como "fazer", como produção material. O exercício de ver que seria próprio da THEORIA se efetivava como elaboração reflexiva mediada pela linguagem, pois se tratava de um "ver conjuntivo", "conceptualmente justificada na interlocução, no falar contraditório com os outros" (Nunes, 2000, p. 20). O que resultava na prevalência do uso da palavra falada sobre o da escrita.

$\mathrm{Na}$ atividade de ensinar pela qual Platão e Aristóteles enveredaram, esse privilégio da oralidade ainda persistia, como se pode inferir pela conhecida recusa de Sócrates em fixar seus ensinamentos 
em obras escritas, a qual foi imitada por seus mais ilustres discípulos que reservaram suas lições fundamentais a um público seleto de iniciados, ministradas mediante a exposição oral e jamais perpetuadas em livros. Nessa direção, Nunes observa que a prática da leitura, na Academia, se realizava em voz alta para que se pudesse recuperar, mesmo que parcialmente, nos diálogos redigidos pelo Mestre, o plano da oralidade, considerado como indispensável à aquisição do saber contido naqueles escritos.

Segundo a narrativa de Benedito Nunes, a filosofia passou a se exercer como ofício à medida em que a escrita se consolidava como recurso indispensável da elaboração reflexiva ao passo que a oralidade parece ter se tornado irrelevante a partir do século XVII, com o início da impressão de livros. Descartes teria encarnado o tipo de filósofo no qual a ação do pensamento já não se realizará mais, predominantemente, sob a modalidade da "dialogação". Sua tarefa se realizará como produção escrita, embora não dispense o diálogo interior que marcará a atitude individualista do autor moderno. Fundem-se, então, a partir daí, nos livros de fílosofia, o "afazer" - ação do pensamento, privada e introspectiva, destinada à elaboração reflexiva de conceitos - e o "fazer" filosófico, produção escrita de teses e tratados para fins de comunicação impessoal e à distância.

Essa narrativa sustenta que, de certa maneira, apesar do declínio da "dialogação" como elemento da prática filosófica, a palavra falada ainda exerce um papel indispensável na prática da filosofia, seja como ensinamento seja como aprendizagem. Benedito Nunes entende que toda atividade filosófica se constitui de três componentes indissociáveis: a teoria, a ação do pensamento e a produção de texto (2000, p. 25). Ao longo da história, esses elementos persistiram como componentes específicos da filosofia na "dialogação" platônica, na estrutura das Sumas, na disputatio e na quodilibetale, nas Meditações de Descartes e nos tratados que, a partir do século XVII, se estabeleceram como gênero literário próprio da filosofia moderna e contemporânea.

\section{O ENSAIO COMO ATIVIDADE FILOSÓFICA POR EXCELÊNCIA}

A elaboração discursiva de conceitos, isto é, de objetos dispostos para a visão do espírito, afeta, antes mesmo dos interlocutores, o próprio filósofo, que, ao ordenar as palavras para dar à luz um conhecimento retirado da sensação, da memória, da imaginação, da linguagem ou da inteligência, modifica sua própria relação com o real. O lançamento dessas ideias ao jogo dos debates e das objeções dá continuidade à ação do pensamento, que, doravante, se estenderá da esfera da introspecção para a da crítica, da contradição e da reelaboração. Embora a "dialogação", como expressão viva da fala pública, tenha cedido espaço para a escrita, ela costuma se recuperar pela leitura e, no campo da docência, nada impede que se lance mão de recursos didáticos que se apoiem em experiências de oralidade para que a leitura se estenda para além da decodificação do leitor solitário e possa ativar o pensamento como ação no circuito de uma coletividade.

Nas condições em que a atividade filosófica de fato se exerce na atualidade, a erudição se tornou uma meta quase impossível no que tange à formação da juventude. Entretanto, a inquietação e a curiosidade, que impulsionam essa atividade, não se contêm nos limites estabelecidos pelos agenciamentos da burocracia institucional. Desde o Parecer 277/62, do Conselheiro Newton Sucupira, no Conselho Nacional de Educação, a prevenção do proselitismo tem sido preconizada a partir da afirmação da essência da filosofia como um saber plural ao qual o acesso se dá, eminentemente, pela leitura de obras clássicas. Tais orientações também contemplam a vontade de assegurar que o ato docente se efetive como um impulsionador da inquietação e da curiosidade sem 
os quais o contato com os textos de filosofia se limita à apreensão do conteúdo da história da filosofia, sem habilitar o estudante ao pensamento emancipador.

A questão do exercício da atividade filosófica e sua relação com a formação em filosofia tem sido um objeto central do debate filosófico da Modernidade, no qual se destacam os herdeiros do pensamento kantiano, como Michel Foucault. Em seus escritos, podemos encontrar esse debate sob a forma de uma problematização da tarefa e da justificação da filosofia face à História da Humanidade e aos eventos que constituem o presente. Sem dúvida, a filosofia não pode justificarse como componente curricular na escola somente com base em sua contribuição para a aquisição de competências e habilidades instrumentais e tampouco pelo seu potencial de despertar sentimentos morais e cívicos. Para que ela seja consequente, é preciso reconhecer sua capacidade de inquietação e defini-la como atividade problematizadora. Para Foucault, o que faz com que a atividade filosófica alcance essa capacidade e se justifique teórica e moralmente como tarefa intelectual face ao presente é o Ensaio.

Mas o que é filosofar hoje em dia - quero dizer, a atividade filosófica senão o trabalho crítico do pensamento sobre o próprio pensamento? Se não consistir em tentar saber de que maneira e até onde seria possível pensar diferentemente em vez de legitimar o que já se sabe? Existe sempre algo de irrisório no discurso filosófico quando ele quer, do exterior, fazer a lei para os outros, dizer-lhes onde está sua verdade e de que maneira encontrá-la, ou quando pretende demonstrar-se por positividade ingênua; mas é seu direito explorar o que pode ser mudado, no seu próprio pensamento, através do exercício de um saber que lh é estranho. O "ensaio" - que é necessário entender como experiência modificadora de si no jogo da verdade, e não como apropriação simplificadora de outrem para fins de comunicação - é o corpo vivo da filosofia, se, pelo menos, ela for ainda hoje o que era outrora, ou seja, uma "ascese", um exercício de si no pensamento (Foucault, 2001, 13).

O ensaio, tal como Foucault o concebe, nos parece uma experiência propiciadora dessa pretensão de articular a leitura, a escrita e a "dialogação" como atividades próprias de um programa "antipedagógico", isto é, voltado para a irresignação e a integridade intelectual, no qual o pensar não se limita ao aprendizado de comandos, à capacitação profissional nem à assimilação do deveres cívicos, mas se propõe como trabalho incessante de ampliação da liberdade, como esforço permanente de escuta das formas multifacetadas dos discursos, da enunciação da verdade, como intervenção sobre o presente e ação modificadora de si.

$\mathrm{Na}$ aula de 5 de janeiro de 1983, do curso O Governo de Si e dos Outros, analisando o artigo sobre a Aufklärung, de 1784, Foucault remete os ouvintes ao ensaio publicado por Kant no mesmo ano, a propósito da História Universal de um Ponto de Vista Cosmopolita, para mostrar-lhes uma relevante diferença desse texto em relação à sua Resposta à pergunta "Que é Esclarecimento? (Aufklärung): Neste artigo, Kant atribuíra ao soberano da Prússia o papel de garantidor da inserção da humanidade na senda do esclarecimento ao passo que, no ensaio sobre a História Universal, esse papel passará a ser cumprido pela Revolução. O sucesso ou o fracasso do esforço ou do compromisso empenhados é o que menos importa nessa analogia. O ponto decisivo é a marca inconteste do reconhecimento por todos os espectadores aos direitos à liberdade de expressão e à sublevação do povo. Nesse entusiasmo popular, segundo Foucault, Kant assentava sua convicção a propósito do caráter necessário do progresso da humanidade.

A presença da filosofia no cenário cultural do presente é indissociável dessa perspectiva revolucionária apontada por Kant. A educação pública, tal como a conhecemos, é um componente 
central desse cenário. Os objetivos explicitados pela legislação aos quais as instituições de ensino têm o dever de buscar não fazem sentido a não ser sob a perspectiva das mudanças políticas como horizonte da vontade coletiva. Mudanças que requerem, como condição para a formulação de seus termos, a diversidade de pontos de vista, o debate, o contraditório, a manifestação pública das aspirações individuais e coletivas.

Nesta linha, talvez possamos explorar alguns dos estudos de Foucault dedicados às experiências da parrêsia, desenvolvidos em seus Cursos no Colégio de França, sobretudo, A Hermenêutica do Sujeito (1981-1982), O Governo de Si e dos Outros (1982-1983) e A Coragem da Verdade (19831984). Eles nos fornecem os elementos para tirar do silêncio os exercícios de leitura e escrita de textos filosóficos de modo a torná-los "perturbadores", no sentido ressaltado por Ernani Chaves (2017, p. 142) a propósito da tarefa e do traço diferenciador da atividade filosófica, tal como esta foi exercitada por Foucault e Nietzsche. Trata-se de enveredar pela relação do filósofo com a política, no campo da prática de enunciação da verdade em vista do governo de si e dos outros. Trata-se de reconhecer que o exercício da filosofia não pode ser dogmático nem doutrinário, mas também não pode ser isento nem imparcial, uma vez que tem de se posicionar em relação aos desafios concretos da existência comum da humanidade.

\section{CONSIDERAÇÕES FINAIS}

A democratização do acesso à escola, de fato, alterou as condições nas quais o exercício do afazer e do fazer da filosofia passaram a se realizar. Foi com base nessa realidade que se promoveram as reformas para substituir a erudição pela aquisição de competências e habilidades como diretrizes dos currículos escolares e universitários. Atribui-se à densidade do currículo do Ensino Médio e à suposta doutrinação ideológica o baixo desempenho dos estudantes nas avaliações internacionais. Contudo, tais inferências são correlativas à omissão de fatores cruciais para a formação de um entendimento justo acerca da eficácia da ação educativa institucional em nosso país. Entre tais fatores, destacam-se a formação do professor em nível superior e as condições institucionais e de infraestrutura do trabalho docente.

A partir dessas premissas entendemos que a docência em filosofia na Educação Básica pode se beneficiar de atividades que envolvam a elaboração de ensaios mediante os quais estudantes e professores de filosofia do ensino médio tenham acesso a subsídios para a realização de seminários, debates, encontros, diálogos e outras atividades facilitadoras da aprendizagem na quais se possa exercitar, mediante o uso da palavra falada, o "pensamento filosófico" e não somente alcançar o conhecimento da "história da filosofia". A despeito da centralidade do caráter propedêutico pelo qual se tem justificado a filosofia como disciplina no currículo do ensino médio, sustentamos que essa presença será irrelevante caso se limite a prover conhecimentos técnicos, preceitos morais e fundamentos epistemológicos para a inserção dos estudantes no mundo do trabalho, na esfera da cidadania e na do ensino superior. Sua contribuição para a formação das pessoas não poderá ocorrer sem que ela seja capaz de "perturbar" a ordem sob a qual lidamos com a verdade, o poder e a subjetividade. O que implica a necessidade de proporcionar aos estudantes oportunidades para fazerem a experiência das diferentes atitudes que o filósofo pode e tem assumido em relação à vida política: como legislador, como pedagogo ou como transgressor, isto é, como cínico (Chaves, 2017, p. 40).

UFAMBR, Manaus, v. 2, n. 1, art. 8, pp. 83-93, janeiro-junho, 2020 http://www.periodicos.ufam.edu.br/ufambr 
Assim, concebemos esses ensaios como introdução aos modos foucaultianos de leitura e escrita de textos filosóficos destinados a explorar a situação e o papel da história da filosofia como base indispensável ao exercício do pensamento filosófico, considerado como uma investigação histórico-crítica da atualidade. Tais ensaios poderão se apresentar como instrumentos de facilitação do trabalho do professor de filosofia e como subsídio para o desenvolvimento de atividades de leitura, redação e debates entre os estudantes do ensino médio. Esperamos alcançar a produção de materiais que, sem cair na banalização superficial, deverão proporcionar o acesso do público ao qual se destinam a uma maneira de pensar que jamais buscou se consolidar como doutrina e que somente se tornou relevante enquanto se manteve atenta contra os abusos dos déspotas, dos legisladores e dos pedagogos da filosofia.

\section{REFERÊNCIAS}

Alves, D. J. (2002). A filosofia no ensino médio ambiguidade e contradições na LDB; Campinas/SP: Autores Associados.

Alves, D. J. (2005). Diretrizes Curriculares Nacionais para os Cursos de Graduação em Filosofia: o papel da licenciatura no processo de formação filosófico-pedagógica; tese de doutorado; Campinas: Unicamp.

República Federativa do Brasil. (2008). Lei $\mathrm{n}^{\text {o. }}$ 11.684/2008. In: http://www.planalto.gov.br/ccivil_03/_Ato2007-2010/2008/Lei/L11684.htm (consulta em 24/01/2019; às 18:24).

República Federativa do Brasil. (2014). Ministério da Educação, Plano Nacional de Educação Linha de Base. In http://portal.inep.gov.br/documents/186968/485745/Plano+Nacional+de+Educa\%C3\%A7 \%C3\%A3o+PNE+2014-2024++Linha+de+Base/c2dd0faa-7227-40ee-a52012c6fc77700f?version=1.1 (consulta em 24/01/2019; às 18:17).

República Federativa do Brasil. (2014). Ministério da Educação, Plano Nacional de Educação 2014-2024. In: http://pne.mec.gov.br/18-planos-subnacionais-de-educacao/543-planonacional-de-educacao-lei-n-13-005-2014. (consulta em 24/01/2019; às 16:23).

República Federativa do Brasil. (2015). Resolução no. 2, de $1^{\circ}$. de julho de 2015, do Conselho Pleno do Conselho Nacional de Educação; define as Diretrizes Curriculares Nacionais para a formação inicial em nível superior (cursos de licenciatura, cursos de formação pedagógica para graduados e cursos de segunda licenciatura) e para a formação continuada. http://portal.mec.gov.br/docman/agosto-2017-pdf/70431-res-cne-cp-002-03072015pdf/file.

República Federativa do Brasil. (2017). Resolução CNE/CP no 2, de 22 de dezembro de 2017; Institui e orienta a implantação da Base Nacional Comum Curricular, a ser respeitada obrigatoriamente ao longo das etapas e respectivas modalidades no âmbito da Educação Básica.

In: http://portal.mec.gov.br/index.php?option=com_docman\&view=download\&alias=79631- 
rcp002-17-pdf\&category_slug=dezembro-2017-pdf\&Itemid=30192. （Consultado em 03/02/2019, às 19:27).

Brasil. Lei $\quad \mathrm{N}^{\text {o. }}$ 13.415/2017. In: http://www.planalto.gov.br/ccivil_03/_Ato20152018/2017/Lei/L13415.htm (consulta em 24/01/2019; às 18:28).

Chaves, E. (2017). Cinismo e Política ou a história da filosofia insurreta de Michel Foucault; in RAGO, Margareth e GALLO, Sílvio (Org.) Michel Foucault e as insurreições É inútil revoltar-se? São Paulo: CNPQ, CAPES, FAPESP, Intermeios. Páginas 133-142.

Foucault, M. (2000). 1984 - O Que São as Luzes? in: Michel Foucault. Arqueologia das Ciências e História dos Sistemas de Pensamento Ditos \& Escritos II; organização de Manoel Barros da Motta; tradução de Elisa Monteiro; Rio de Janeiro: Forense-Universitária.

. (2001). História da Sexualidade 2 o uso dos prazeres. Tradução de Maria Thereza da Costa Albuquerque; revisão técnica de José Augusto Guilhon Albuquerque; $9^{\mathrm{a}}$. Edição; Rio de Janeiro: Graal.

. (2010). A Hermenêutica do Sujeito: curso dado no Collège de France (19811982). Tradução de Márcio Alves da Fonseca e Salma Tannus Muchail; $3^{\text {a }}$. Edição; São Paulo: WMF Martins Fontes.

. (2010). O Governo de Si e dos Outros: curso dado no Collège de France (1982-1983). Tradução de Eduardo Brandão; São Paulo: WMF Martins Fontes.

(2011). A Coragem da Verdade: curso dado no Collège de France (19831984). Tradução de Eduardo Brandão; São Paulo: WMF Martins Fontes.

Freire, Paulo. (1989). A Importância do Ato de Ler: em três artigos que se completam; São Paulo: Autores Associados: Cortez.

Kant, Immanuel. (1985). Resposta à pergunta: Que é "Esclarecimento”? (“Aufklärung”). in: Immanuel Kant Textos Seletos; edição bilingue; tradução de Raimundo Vier; Introdução de Emmanuel Carneiro Leão; $2^{a}$. Edição; Petrópolis: Vozes.

Kant, Immanuel. (1986). Ideia de uma História Universal de um Ponto de Vista Cosmopolita. Ricardo R. Terra (org.); tradução de Rodrigo Naves e Ricardo R. Terra; edição bilingue; São Paulo: Brasiliense.

Kant, Immanuel. (1992). Anexo: notícia do Prof. Immanuel Kant sobre a organização de suas preleções para o semestre de inverno de 1765-1766. In: Lógica; tradução de Guido Antônio de Almeida; Rio de Janeiro: Tempo Brasileiro.

Muchail, Salma T. (1995). Ler, Escrever, Pensar (notas sobre o ensino de filosofia); in: Filosofia e seu Ensino (Paulo Arantes, Franklin Leopoldo e Silva, Celso Favaretto, Ricardo Fabrini, Salma T. Muchail [orgs.]); 2a . Edição; Petrópolis, RJ: Vozes; São Paulo: Educ. 
Muchail, Salma T. (2004). A trajetória de Michel Foucault; In: Foucault Simplesmente textos reunidos. São Paulo: Loyola.

Nunes, Benedito. (2000), O fazer filosófico ou oralidade e escrita em Filosofia. In: Dois ensaios $e$ duas lembranças. Belém: SECULT/UNAMA. 